\title{
A METHOD OF COMPLEX EVALUATION OF MORPHOLOGICAL STRUCTURE OF OSTIOMEATAL COMPLEX COMPONENTS, LOWER WALL OF MAXILLARY AND FRONTAL SINUSES
}

10.36740/WLek202012104

\author{
Victoriia V. Alekseeva ${ }^{2}$, Alina S. Nechiporenko', Andrii V. Lupyr ${ }^{2}$, Nadiia 0. Yurevych'², Vitaliy V. Gargin² \\ 'KHARKIV NATIONAL UNIVERSITY OF RADIOELECTRONICS, KHARKIV, UKRAINE \\ ${ }^{2}$ KHARKIV NATIONAL MEDICAL UNIVERSITY, KHARKIV, UKRAINE
}

\begin{abstract}
The aim: Was to evaluate the anatomical variability of the frontal and maxillary sinuses, ostiomeatal complex components (OMC) and to identify factors that contribute to complications of inflammatory processes and development of odontogenic maxillary sinusitis.

Materials and methods: The study involved assessment of 100 spiral computed tomograms (SCT) of human patients without pathological processes in the PNS area. The basic parameters of the anatomical structure of the ostiomeatal complex (the area of the hooked process and the middle nasal conch, their transverse dimensions, the density and dimensions of the natural connection), the thickness and the density of the lower wall of the maxillary and frontal sinuses were determined. These parameters were investigated by the method of uncertainty calculation.

Results: The findings showed that the bone density of the maxillary sinus on the left was $57.713 \pm 440.356 \mathrm{Hu}$ (minimum), $1101.507 \pm 613.4882 \mathrm{Hu}$ (maximum); $96.2752 \pm$ 395.0 and $1028.691 \pm 620.4051$ on the right, respectively, the density of the inferior frontal sinus wall on the right was $5.5179 \pm 276.43$ and $831.1607 \pm 732.274$, on the left $12.069 \pm 310.56$ and $898.293 \pm 748$, respectively. In the same way, the probable OMC structure parameters, in the range $\pm U$ at the confidence level $p=0.95$, were calculated. Conclusions: Thus, some variants of the anatomical structure of the ostiomeatal complex can be a prerequisite for hypoventilation of PNS and, as a consequence, lead to inflammatory processes in them. Features of the same structure of the walls of the PNS are a prerequisite for the propagation of the inflammatory process in the surrounding tissues and the development of complications.
\end{abstract}

KEY WORDS: spiral computed tomography, paranasal sinuses, ostiomeatal complex, density, calculation of uncertainty

Wiad Lek. 2020;73(12 p. I):2576-2580

\section{INTRODUCTION}

Much attention has always been paid to the study of the anatomical structure of the paranasal sinuses (PNS). The main achievements in the study of this area of the human skull date back to the late $19^{\text {th }}-$ early $20^{\text {th }}$ centuries [1]. For the most part, the study of PNS was carried out on cadaveric material, or at best, in the study of scanned radiographs of the skull in different projections, which caused inconvenience and some errors in the study and description of anatomical structures.

A new turn in the study of PNS is due to the rapid development of computed tomography (CT), a fundamentally new, informative, in vivo method of investigating anatomical structures in general, and PNS in particular [2]. According to new recommendations in the diagnosis of inflammatory processes of PNS (rhinosinusitis), CT is the "gold standard" for the diagnosis of this group of diseases. [3]. In addition, a fairly new method of treating PNS diseases, namely functional endoscopic sinus surgery is currently being developed, which raises the standard of living, improves prognosis for patients with chronic rhinosinusitis [4] and at the same time also requires detailed knowledge of the features of the structure of PNS, ostiomeatal complex structure, enabling the operative access to the frontal and maxillary sinuses and their physiological functioning. The development of chronic inflammatory processes in PNS is associated with changes not only in the mucosa [5] but also in the microarchitectonics of bone tissue.

To date, the number of complications of rhinosinusitis [6] and the proportion of odontogenic maxillary sinusitis is steadily increasing as well, accounting for up to $40 \%$ of all cases of maxillary sinusitis. The main factors contributing to the development of complications are the density and thickness of PNS bone tissue. Osteitis Scoring Scale, according to Georgalas et el, reflects the extent of bone destruction [7], where the degree of bone destruction was determined by calculating the thickness and extent of involvement of the sinus wall.

According to Dong et al [8], the degree of bone destruction exceeding its thickness reflects its density. One cannot disagree with each of these assumptions. That is why this study is dedicated to the joint study of two parameters, thickness and density.

\section{THE AIM}

Considering all of the above, the aim of our study was to evaluate the anatomical variability of the frontal and 

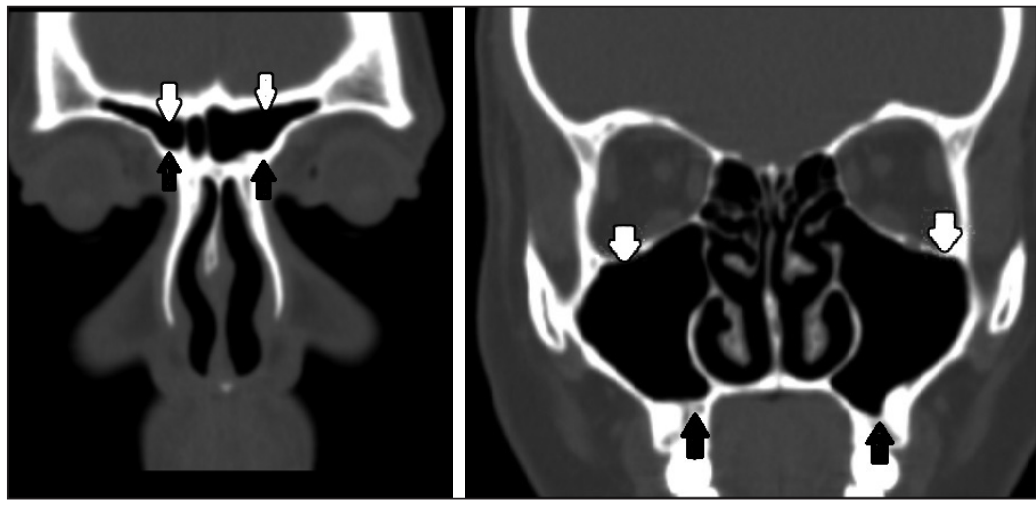

Fig.1. Visualization of the anatomical structures of the maxillary sinus and frontal sinuses. O- Upper walls

- Lower walls

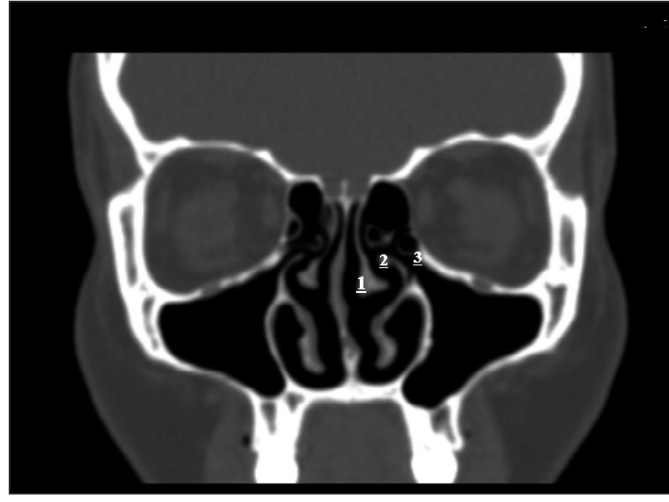

Fig.2. Spiral computed tomogram of a patient with visualization of OMC components at the slice $(1$ - middle nasal concha, 2 - uncinated process, 3 - anastomosis) maxillary sinuses of the human, ostiomeatal complex components and to identify anatomical factors that contribute to the complication of inflammatory processes and development of odontogenic maxillary sinusitis.

\section{MATERIALS AND METHODS}

The study involved evaluation of 100 spiral computed tomograms (SCT) of humans without pathological processes in PNS area. The study was conducted for a reason unrelated to ENT diseases (suspected unconfirmed stroke, etc.). Male and female 18- to 40-year-old patients were monitored. The attention was paid to the study of the walls of the maxillary sinus in connection with the most frequent pathological conditions, caused by the largest among all PNS sizes, the proximity of the location of the teeth and the low location relative to the natural connection with the nasal cavity. Equally important was the study of the structure of the frontal sinus in connection with the possibility of the development of severe intracranial and intra-orbital complications of inflammatory processes. The density and thickness of the lower wall of the frontal sinus and the lower wall of the maxillary sinus were studied. The basic parameters of the anatomical structure of the ostiomeatal complex (the area of the hooked process and the average nasal conch, their transverse dimensions, density and dimensions of natural connection) were also determined. Due to complexity of identification of points and segments for both density and thickness calculations, the study used the method of calculating uncertainty for density and thickness values. Uncertainty is a fairly new concept in medicine that has been used so far in laboratory diagnosis. It points to a variety of values of a certain magnitude that are statistically reliable.

To calculate this index, the maximum and minimum density, expressed in Hunsfields $(\mathrm{Hu})$, maximum and minimum wall thickness in millimeters (see Fig. 1), maximum and minimum thickness of the middle nasal conch, hooked process and natural connection were determined throughout the study wall as the main components of the ostiomeatal complex (see Fig. 2).
All inputs of input uncertainty form a standard uncertainty. To calculate the standard uncertainty we used the formula:

$$
\mathrm{u}_{\mathrm{c}}\left(\mathrm{H}_{\mathrm{H}}\right)=\mathrm{u}_{\mathrm{A}}^{2}\left(\mathrm{H}_{\mathrm{Hi}}\right)+\mathrm{u}_{\mathrm{B}}^{2}\left(\mathrm{H}_{\mathrm{Hi}}\right)
$$

where $u_{A}\left(H_{H i}\right)$ is a standard type A uncertainty, a $u_{B}\left(H_{H i}\right)$ is a standard type B uncertainty.

Standard type A uncertainty was calculated using the formula:

$$
\mathrm{u}\left(\mathrm{H}_{\mathrm{Hi}}\right)=\sqrt{\frac{1}{n(n-1)} \sum_{i=1}^{n}\left(H_{H i}-H_{H}\right)^{2}}
$$

where $H_{H i}$ - $\mathrm{i}$-th value of the sample measurements, $\mathrm{H}_{\mathrm{H}}$ is the mathematical expectation, $\mathrm{n}$ is the number of measurements in the sample.

Standard type B uncertainty was calculated using the formula:

$$
u\left(H_{H}\right)=H_{H} \frac{\delta_{H}}{\sqrt{3} \cdot 100}
$$

Where $d_{H}$ is a measurement error of software not exceeding 0.0001 .

After calculating these values, an interval estimation of uncertainty was calculated, namely extended uncertainty $\mathrm{U}$ according to the formula:

$\mathbf{U}=\mathbf{k} \mathbf{u}_{c}$

where $\mathrm{k}$ is the coverage ratio.

Similarly to the given algorithm, the uncertainty of the thickness of the hooked process $(\mathrm{Uu})$, the middle nasal conch $(\mathrm{Um})$, and the natural connection (Un) was calculated.

\section{RESULTS}

The results of the uncertainty calculation are given in Tables I-IV.

As can be seen from the table (see Table I, II), the probable values of $Y$ are in the range $\pm U$ relative to the measured value of $y$, and the degree of validity of $Y$ values in this interval is determined by the probability (confidence level) $p=0.95$

In the same way, according to Table 2 , the probable indicators of the OMC structure, which are in the range $\pm \mathrm{U}$ at the confidence level $\mathrm{p}=0.95$, were calculated. 
Table I.Total standard measurement uncertainty of the thickness of the lower wall of the maxillary and frontal sinuses

\begin{tabular}{|c|c|c|c|c|c|c|c|c|}
\hline \multirow{3}{*}{ Name } & \multicolumn{4}{|c|}{ Thickness of the lower wall of the maxillary sinus } & \multirow{2}{*}{\multicolumn{4}{|c|}{$\begin{array}{c}\text { Thickness of the lower wall of the frontal sinus } \\
\text { On the left }\end{array}$}} \\
\hline & \multicolumn{2}{|c|}{ On the left } & \multicolumn{2}{|c|}{ On the right } & & & & \\
\hline & Minimum & Maximum & & Minimum & Maximum & & Minimum & Maximum \\
\hline $\mathrm{U}_{\mathrm{H}}(\mathrm{mm})$ & 0,25342013 & 3,6419141 & 0,25794 & 1,2 & 2,8695 & 1,7217 & 1,2386 & 2,1105 \\
\hline $\mathrm{U}_{\text {extend }}(\mathrm{mm})$ & 0,506840025 & 7,2838282 & 0,515898223 & 2,4 & 5,7389 & 3,4433 & 2,4771 & 4.221 \\
\hline $\mathrm{Y}(\mathrm{mm})$ & 1,45 & 9,94 & 0,895 & 2,17 & 2,0422 & 4,375 & 2,29 & 4,05 \\
\hline
\end{tabular}

Table II. Total standard measurement uncertainty of the density of the lower wall of the maxillary and frontal sinuses

\begin{tabular}{|c|c|c|c|c|c|c|c|c|}
\hline \multirow{3}{*}{ Name } & \multicolumn{4}{|c|}{ Density of the lower wall of the maxillary sinus } & \multicolumn{4}{|c|}{ Density of the lower wall of the frontal sinus } \\
\hline & \multicolumn{2}{|c|}{ On the left } & \multicolumn{2}{|c|}{ On the right } & \multirow[b]{2}{*}{ Maximum } & & \multicolumn{2}{|c|}{ On the left } \\
\hline & Minimum & Maximum & & Minimum & & & Minimum & Maximum \\
\hline $\mathrm{U}_{\mathrm{p}}(\mathrm{Hu})$ & 220,178 & 306,7441 & 197,617 & 310,2026 & 155,282 & 374,24 & 138,217 & 366,1371 \\
\hline $\mathrm{U}_{\text {extend }}(\mathrm{Hu})$ & 440,356 & 613,4882 & 395,0 & 620,4051 & 310,56 & 748,48 & 276,43 & 732,274 \\
\hline $\mathrm{Y}(\mathrm{Hu})$ & 57,713 & 1101,507 & 96,2752 & 1028,6 & 12,07 & 898,29 & 45,52 & 831,16 \\
\hline
\end{tabular}

Table III. Calculation of uncertainty of anatomical parameters of middle nasal concha

\begin{tabular}{|c|c|c|c|c|}
\hline \multirow{2}{*}{ 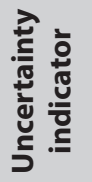 } & \multicolumn{4}{|c|}{ Parameter under study } \\
\hline & Density,Hu & Area, $\mathbf{M m}^{2}$ & Maximum width, mm & Minimum width, $\mathrm{mm}$ \\
\hline$U_{a}$ & 98.745441 & 114.70604 & 3.488279101 & 12.1277619 \\
\hline$U_{b}$ & 0.0001352 & $-5.4008 \mathrm{E}-05$ & 3.90629E-06 & $1.86242 \mathrm{E}-06$ \\
\hline $\mathrm{U}_{\mathrm{s}}$ & 98.745441 & 114.706039 & 3.488279101 & 12.1277619 \\
\hline$U_{e x}$ & 197.49088 & 229.412078 & 6.976558202 & 24.2555237 \\
\hline
\end{tabular}

Table IV. Calculation of uncertainty of anatomical parameters of uncinated process and natural anastomosis

\begin{tabular}{|c|c|c|c|c|c|}
\hline \multirow{2}{*}{ 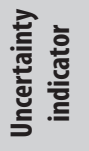 } & \multicolumn{5}{|c|}{ Parameter under study } \\
\hline & Density, Hu & Area, $\mathrm{mm}^{2}$ & Maximum width, mm & Minimum width, mm & Anastomosis \\
\hline$U_{a}$ & 89.86946776 & 92.61977836 & 1.055116952 & 0.743679843 & 1.012820123 \\
\hline$U_{b}$ & 0.000136564 & $4.50282 \mathrm{E}-05$ & $1.9266 \mathrm{E}-06$ & $7.69061 \mathrm{E}-07$ & 3.02047E-06 \\
\hline Us & 89.86946776 & 92.61977836 & 1.055116952 & 0.743679843 & 1.012820123 \\
\hline$U_{e x}$ & 179.7389355 & 185.2395567 & 2.110233904 & 1.487359686 & 2.025640245 \\
\hline
\end{tabular}

Based on the data obtained during the study, it can be said that the bone density maxillary sinus on the left is $57.713 \pm 440.356 \mathrm{Hu}$ (minimum), $1101.507 \pm 613.4882$ $\mathrm{Hu}$ (maximum); 96.2752 \pm 395.0 and $1028.691 \pm 620.4051$ on the right respectively, lower frontal sinus density on the right is $5.5179 \pm 276.43$ and $831.1607 \pm 732.274,12.069$ \pm 310.56 and $898.293 \pm 748.48$ on the left (see Table II), respectively in the order above.

\section{DISCUSSION}

Currently, there is a considerable amount of research on human PNS. Until now, they have been based largely on the determination of wall thickness, as in the case of the given destruction scale [7]. Very rarely, bone density was considered as an indicator of its destruction only in laboratory animals [8]. In our opinion, it would be advisable to take a comprehensive approach to the study of these parameters. After the study, we can assume that sinuses with bone density less than the minimum in physiological conditions can be attributed to the group of sinuses with low density, which may be a prerequisite for the rapid spread of pathological process with the development of complications. Also, the development of pathological processes in the sinuses, the thickness of which is less than the minimum defined in the study, may be unfavorable. However, special attention should be paid to sinuses with a combination of these factors - thin walls with low density. 
This combination can be especially dangerous in women during menopause [9].

The main prerequisite for the development of inflammatory processes in the paranasal sinuses is its inadequate ventilation [10]. Thus, it is extremely important to know the features of the anatomical variability of the components that make up the ostiomeatal complex. The study involved measurement of the area, transverse dimensions of its main components (uncinated process, middle nasal concha, natural anastomosis). Peculiarities of the anatomical structure of the area of the ostiomeatal complex in combination with a decrease in local immunity [11] in the presence of viral, bacterial, fungal or combined microflora become the main prerequisite for the development of inflammatory processes in the area of the paranasal sinuses [12].

To date, much attention has been paid to the topic of the anatomical structure of the ostiomeatal complex. There have been studies dealing with measurement of its individual parameters (thickness or density) [13]. However, a comprehensive assessment of them has not been carried out so far. It is quite interesting to study the rate of air flow through the ostiomeatal complex [14], however, this technique is invasive and is performed intraoperatively, and therefore the doctor does not fully understand the condition of the ostiomeatal complex and the volume of surgery until its beginning. Therefore, a comprehensive calculation of the anatomical parameters of the ostiomeatal complex would allow, before the start of surgical treatment, to select a group of patients, requiring determination of the flow rate of air through the natural connection and in case of confirmed obstruction of the junction to carry out intraoperative expansion or combine it with laser or other treatment in case of enlargement of the middle nasal concha. Therefore, it can be assumed that such a group of patients would include persons with sizes of the middle nasal concha larger than the maximum in this study (see Tables III, IV). Equally important was the measurement of the size of the junction. In cases where they are smaller than the size of the sinuscope, it would be more expedient to give preference to other ways of accessing the PNS (in particular, microscopic maxillary sinusotomy or access through the alveolar socket in the odontogenic form of maxillary sinusitis).

Thus, not only the condition of the mucous membrane $[15,16,17]$, but also the condition of the bone tissue of the paranasal sinuses is essential for the successful treatment of diseases of the jaw and dento-facial system. Thus, the study allowed us to determine the group of persons who require comprehensive, careful and thorough examination to detect possible pathological processes in PNS. These are patients with low (less than minimal in physiological conditions) bone density in combination with low bone thickness. In the same group of patients there is also a risk of incorrect loading during dental implantation with the development of odontogenic maxillary sinusitis. In terms of surgery, it is advisable to pay special attention to a group of people with a large area of both the hooked process and the middle nasal concha, which is combined with larger than certain maximum transverse dimensions [18]. This should take into account the features of both general and local biomineralization of tissues in physiological and pathological processes [19], the importance of timely diagnosis of pathological processes of this localization, including in the presence of their unconventional course [20], as well as features of the influence of environmental factors on the morpho- functional state of the investigated tissues [21], and their regeneration [22,23]. Also it could be actual for performing of epidemiological anthropometric research [24].

This study makes it possible to comprehensively evaluate, using a fundamentally new method of uncertainty calculation, such extremely important elements of the structure of the paranasal bone tissue as thickness and density, as well as to calculate the morphological characteristics of the ostiomeatal complex, whicg is the key for the normal functioning of the sinus area.

\section{CONCLUSIONS}

Thus, some variants of the anatomical structure of the ostiomeatal complex can be a prerequisite for hypoventilation of PNS and, as a consequence, result in inflammatory processes in them. Features of the same structure of the walls of the PNS are a prerequisite for the propagation of the inflammatory process in the surrounding tissues and the development of complications. A timely diagnosis, successful treatment and prevention of complications requires a comprehensive assessment of all anatomical structures of the PNS. Determining one or more indicators of constitution can lead to diagnostic errors and complications of inflammatory processes in this area.

\section{REFERENCES}

1. Onodi A., Thomson S.C. The anatomy of the nasal cavity and its accessory sinuses: an atlas for practitioners and students. London: H.K. Lewis. 1895.

2. du Plessis A., Broeckhoven C., Guelpa A., le Roux S.G. Laboratory x-ray micro-computed tomography: a user guideline for biological samples. Gigascience. 2017;6(6):1-11. doi: 10.1093/gigascience/gix027.

3. Fokkens W.J., Bachert C., Bernal-Sprekelsen M., Bousquet J. et al. Rhinology Future Debates. EUFOREA Report. Rhinology. 2017;55(4):298-304. doi: 10.4193/Rhin17.221

4. Jain R., Kumar H., Tawhai M., Douglas R. The impact of endoscopic sinus surgery on paranasal physiology in simulated sinus cavities. Int Forum Allergy Rhinol. 2017;7(3):248-255. doi: 10.1002/alr.21879.

5. Denga 0., Pyndus T., Gargin V., Schneider S. Influence of Metabolic syndrome on Condition of Microcirculatory bed of Oral cavity. Georgian Med News. 2017;(273):99-104.

6. Carr T.F. Complications of sinusitis. Am J Rhinol Allergy. 2016;30(4):2415. doi: 10.2500/ajra.2016.30.4322.

7. Georgalas C., Videler W., Freling N., Fokkens W. Global Osteitis Scoring Scale and chronic rhinosinusitis: a marker of revision surgery. Clin0tolaryngol. 2010;35(6):455-61. doi: 10.1111/j.17494486.2010.02218.x.

8. Dong Y., Zhou B., Huang Z., Huang Q. et al. Evaluating bone remodeling by measuring Hounsfield units in a rabbit model of rhinosinusitis: is it superior to measuring bone thickness? Int Forum Allergy Rhinol. 2018;8(11):1342-1348. doi: 10.1002/alr.22205. 
9. Gargin V.V., Alekseeva V.V., Lupyr A.V. et al. Correlation between the bone density of the maxillary sinus and body mass index in women during the menopause. Problemi Endokrinnoi Patologii. 2019; (2): 20-26.

10. Alekseeva V.V., Lupyr A.V., Urevich N.O., Nazaryan R.S. et al. Significance of Anatomical Variations of Maxillary Sinus and Ostiomeatal Components Complex in Surgical Treatment of Sinusitis, Novosti Khirurgii. 2019; 27 (2): 168-176.

11. Koptev M.M., Vynnyk N.I., Kokovska O.V., Pronina 0.M. et al. The use of immunohistochemical methods in the study of morphofunctional features of the human paranasal sinuses: literature review. Wiad Lek. 2018;71(3 pt 2):768-771.

12. Auge J., Vent J., Agache I., Airaksinen L. et al. EAACl Position paper on the standardization of nasal allergen challenges", Allergy. 2018; 73(8): 1597-1608

13. Güngör G., Okur N., Okur E. Uncinate Process Variations and Their Relationship with Ostiomeatal Complex: A Pictorial Essay of Multidedector Computed Tomography (MDCT) Findings. Pol J Radiol. 2016;81:173-80. doi: 10.12659/PJR.895885.

14. Nechiporenko A.S. Rhinomanometric signal processing for selection of formilized diagnostic criterion in rginology. Telecommunications and Radio Engineering. 2015; 74: 1285-1294.

15. Bezruk V., Krivenko S., Kryvenko L. Salivary lipid peroxidation periodontal status detection in ukrainian atopic children with convolutional neural networks. Scientific-Practical Conference Problems of Infocommunications. Science and Technology (PIC S\&T) 2017 4th International. Kharkov, Ukraine. 2017: 122-124.

16. Krivenko S., Krivenko S. Many-to-many linear-feedback shift register. Electronics and Nanotechnology (ELNANO). 2014 IEEE 34th International Conference on. Kyiv, Ukraine. 2014 :176-178.

17. Bezruk V., Krivenko S., Kryvenko L. The Pareto chart of caries intensity evaluation for children with allergic diseases. 2015 Second International Scientific-Practical Conference Problems of Infocommunications Science and Technology (PIC S\&T), Kharkiv, Ukraine, 2015: 110-111.

18. Nechyporenko A.S., Reshetnik V.M., Alekseeva V.V., Yurevych N.O. et al. Assessment of Measurement Uncertainty of the Uncinated Process and Middle Nasal Concha In Spiral Computed Tomography Data. Problems of Infocommunications Science and Technology (PIC S\&T), Kyiv, Ukraine. 2019: 584-587

19. Danilchenko S.N., Kalinkevich A.N., Moskalenko R.A., Kuznetsov V.N. et al. Structural and crystal-chemical characteristics of the apatite deposits from human aortic walls. Interv Med Appl Sci. 2018;10(2):110-119. doi: 10.1556/1646.10.2018.24.

20. Romaniuk À., Lyndin M., Smiyanov V., Sikora V. et al. Primary multiple tumor with affection of the thyroid gland, uterus, urinary bladder, mammarygland and other organs. Pathol Res Pract. 2017 May;213(5):574-579. doi: 10.1016/j.prp.2017.01.003.
21. Avetikov D., Bondarenko V., Danylchenko S., Pronina E. et al. Energy metabolism disorders in rat salivary glands tissues in connection with chronic sodiumnitrate intoxication. Georgian Med News. 2014;(237):76-9.

22. Avetikov D.S., Bukhanchenko 0.P., Ivanytskyi I.0., Aipert V.V. et al. Perspectives for applying the additional study methods for diagnostics optimization of postoperative hypertrophic scars of the head and neck. Wiad Lek. 2018;71(3 pt 1):470-473.

23. Avetikov D., Loza K., Starchenko I., Loza E. et al. Experimentalmorphological substantiation of expediency to use the skin glue "Dermabond" for postoperative wound closure. Georgian Med News. 2015;(244-245):90-3.

24. Hoyer B.B., Ramlau-Hansen C.H., Vrijheid M., Valvi D. et al. Anthropometry in 5- to 9-Year-Old Greenlandic and Ukrainian Children in Relation to PrenatalExposure to Perfluorinated Alkyl Substances. Environ Health Perspect. 2015 Aug;123(8):841-6. doi: 10.1289/ ehp.1408881.

\section{ORCID and contributionship:}

Alina S. Nechiporenko: 0000-0002-4501-7426 C, D, F

Victoriia V. Alekseeva: 0000-0001-5272-8704 A,B,D

Andrii V. Lupyr: 0000-0002-9896-163X ${ }^{D, E, F}$

Nadiia O. Yurevych: 0000-0001-7340-2850 ${ }^{B, D, F}$

Vitaliy V. Gargin: 0000-0001-8194-4019 D, E

\section{Conflict of interest:}

The Authors declare no conflict of interest.

\section{CORRESPONDING AUTHOR Victoriia V. Alekseeva \\ Kharkiv National Medical University \\ 4 Nauky Avenue, 61022 Kharkiv, Ukraine \\ tel:+380999668976 \\ e-mail: vik13052130@i.ua}

Received:09.12.2019

Accepted: 30.08 .2020

A - Work concept and design, B - Data collection and analysis, C - Responsibility for statistical analysis,

$\mathbf{D}$-Writing the article, $\mathbf{E}$-Critical review, $\mathbf{F}$ - Final approval of the article 